\title{
RECAPITULANDO. VOLVER A ERNESTO GUEVARA-EL CHE
}

\author{
Recapitulating. Revisiting Ernesto Guevara-El Che
}

\author{
ILEANA RODRÍGUEZ \\ The Ohio State University (EE.UU.) \\ rodriguez.89@osu.edu
}

\section{Resumen}

Este texto presenta una reflexión sobre el impacto que Ernesto Guevara, El Che, tuvo sobre la inteligencia latinoamericana que reflexiona sobre su vida postmortem. Volver al Che permite recorrer de nuevo los puntos nodales de la historia continental, con sus fallas y aciertos, pero también induce a establecer la relación estrecha entre el pensamiento político y el económico de revolucionarios y reformistas continentales, así como colocar la historia continental dentro de la historia global, sobre todo, la de la relación entre Estados Unidos y la Unión Soviética. La tensión establecida entre las dos potencias condiciona la política de las repúblicas latinoamericanas y las sitúa en un desideratum del cual Fidel Castro y el Che Guevara son los dos exponentes más representativos, colocados en los dos extremos posibles de la historia de nuestra América.

\section{Palabras clave}

Pensamiento político, relación Estados Unidos y Unión Soviética, revolutionarios y reformistas, ficción e historial y entre lo real y lo simbólico. 


\section{Abstract}

This text reflects over the impact Ernesto Guevara, el Che, had over the Latin American intelligentsia that examines his life postmortem. To go back to Che enables us to go over the key points of continental history with its triumphs and defeats and induces to establish a close relationship between the political and economic thought of revolutionaries and reformists, and to locate continental history within global history, above all, that between the United States and the Soviet Union. The tension established between those two powers conditions the type of politics possible in Latin American republics and situates them in a desideratum in which Fidel Castro and Che Guevara are the two most outstanding representatives, located in the two extremes possible of the history of our America

\section{Keywords}

Political thought, relationships between the United States and the Soviet Union, between revolutionaries and reformists, between fiction and history and between the real and the symbolic.

When the night has come and the land is dark and the moon is the only light we'll see...

Darling, Darling, stand by me

Ben E. King, Mike Stoller, Jerry Lieber, Michael Marino. Stand by me.

Pusieron su cuerpo en el patín del helicóptero, informa Jorge Castañeda sobre el cadáver de el Che en su libro La vida en rojo. Una biografía de Che Guevara (1998) y me entra un feroz escalofrío, un sobresalto. Ya sabemos que todo terminó mal, pero la desacralización de ese muerto me sobrepasa. Es la hora del duelo. El Che aflige más muerto que vivo. Ya le habían cortado las manos para sacarle las huellas digitales; ya le habían baleado el cuerpo de abajo para arriba para pretender que había muerto en combate y no a mansalva, con tiros a quema ropa; ya se habían ilusionado con decapitarlo, pero poner la camilla con su cuerpo en el patín de un helicóptero, levantarlo al aire a riesgo de que se les cayera en plena selva boliviana, me asusta porque me recuerda la sentencia "avión y río", que usaban en la Argentina para significar el lanzamiento desde el aire de los cuerpos vivos o no, sanos o drogados, de los detenidos; y me pregunté, en ese mismo instante, cómo era posible que el mayor ícono de la izquierda latinoamericana, el más universal y paradigmático héroe continental, figura emblemática solo comparable culturalmente a los héroes constituidos por los medios masivos en mi generación, James Dean o los Beattles, perdón por la comparación, que gozaban de un mucho mejor megáfono, hubiese terminado así, tendido sobre una batea en el cuarto de lavar del Hospital de Nuestra Señora de Malta en Vallegrande, donde fue trasladado después de ser baleado en un pueblecito de mierda, La Higuera, perdido en los chaparrales, charrales y yuyos, tierra de nadie, confín del mundo del sur de Bolivia. Pero claro, era justamente por eso, por la manera de morir, y no la de vivir; por el modo en que trataron su cuerpo muerto y por el modo en que él trató su cuerpo vivo, que Ernesto Guevara sobrepasó todos los linderos y se catapultó mundialmente en esa frase tan acertada de Fidel Castro que preguntaba en un afiche gigantesco al desembocar en la avenida Santos Suarez de La Habana: “¿Cómo queremos que sean nuestros jóvenes? Queremos que sean como el Che”. La red había sido tirada muy de largo y la cosecha era inconmensurable. 
Así pues, vuelvo a Ernesto Guevara a los 81 años, como vuelve el Entenado, personaje de Juan José Saer, a recordar el cielo en la historia de su captura por los indígenas americanos. Dice:

De estas costas vacías me quedó sobre todo la abundancia de cielo [...]. Y si ahora que soy un viejo paso mis días en las ciudades, es porque la vida es horizontal y disimula el cielo. Allá, de noche, en cambio, dormíamos a la intemperie, casi aplastados por las estrellas [...]. Como si el cielo hubiese sido la pared acribillada de un volcán en actividad que dejase entrever por sus edificios la incandescencia interna. (Saer, 2015: s/p; e-book)

Diminuta una ahora bajo esa incandescencia interna y externa secular que la vida breve de Guevara vivió palmo a palmo; urgencia y audacia de una generación, la mía, cuya experiencia no alcanzan a explicar las caducas categorías de las ciencias sociales cuando vuelven a tirar la mirada por esos mismos pagos. Sólo la poética puede dar cuenta de ello. Ernesto Guevara, el Che, ha dejado de ser una figura política para proyectarse como ícono cultural, emblema. Es así como lo tratan Jorge Castañeda en un libro más sesudo y bien pensado, pero no menos enamorado que el otro, el de Paco Ignacio Taibó II, Emesto Guevara también conocido como el Che ([1996] 2017). Ambos desvelan en su torna vuelta al Che, el poder del afecto y de lo estético. James Dean, el rebelde sin causa, nacido en 1931 y muerto en 1955, era de la misma generación del Che, rebelde con causa, nacido en 1929 y muerto en 1967. Ellos fueron los dos rostros más apetecidos de mi generación, al filo de la segunda guerra europea, ávida de figuras representativas alternativa. Las mujeres adolescentes queríamos conquistar a un hombre de ese talante; al primero, para curarlo de su melancolía y, al segundo, para domarlo, o que nos domara, seguirlo a las guerrillas, ser la favorita como lo hizo Támara Bunke, Tania la guerrillera, o Alicia, la mujer del protagonista de La Vorágine (1924), de José Eustasio Rivera.

Las jóvenes de esa generación oscilábamos entre la enfermedad existencial, l'ennui, el tedio, o la aventura - luego nos desordenaríamos contentas con los Beatles, una música que unía a ambos: John Lennon era del 40, generación que diez años más tarde, la nuestra arrebató. Leyendo a mis 81 años cumplidos, yo soy del 39, esos dos libros sobre el Che que mencioné, constato que, para los hombres, el Che fue el objeto de deseo más grande, mucho más grande que para nosotras, las mujeres, porque, asî como en nosotras predominaba el romanticismo intimista, en ellos, el Che representaba la hombría, la heroicidad, la tenacidad, la valentía, mejor dicho, el arrojo, esa palabra tan desacostumbrada — los jóvenes, como bien interpretó Fidel, aspiraban a ser como el Che. ${ }^{1}$

De todas las obras sobre el Che, estas dos que elijo hoy, en mi vejez, me dejan estupefacta ante lo que se propuso ese hombre, portaestandarte de su generación, que luego se pareó a los más destacados y los sobrepasó. En su saga encontramos todos los leitmotifs de una historia generacional que se literaturizó en novelas de la resistencia y promovió en ensayos sobre la liberación, llamados hacia la audacia de la práctica política y convocatorias del sentido de lo extraordinario. Imaginábamos lo imposible. Su gesta terminó en derrota, cierto. Calculó mal su falta absoluta de recursos, la fuerza y el empuje de un capitalismo imparable, que trabaja alrededor del reloj con horarios que combinan la noche asiática con el día americano; calculó mal su materialidad precaria pero no su empuje que sólo puede ser recogido como se debe en las historias de la heroicidad en la ficción y del cálculo de la iniciativa voluntarista propias de la novela de espionaje y contra espionaje.

Totalmente anti-burgués y guerrillero sempiterno, inauguró el estilo hippie desaliñado en el vestir que imitamos toda una generación fachosa y de apariencia desenfadada. Andaba siempre hediondo, dicen, oliendo a mochila, a cuero viejo y a todo diablo. Su perfil psicológico se sintetiza en un desafío a la muerte tan feroz como su sentido providencial de la vida. Se sentía y se sabía llamado y elegido. Sus rasgos son todos de una personalidad áspera: coraje, organización, disciplina, humor cáustico, difícil cercanía,

\footnotetext{
${ }^{1}$ La versión más completa de los libros publicados sobre el Che es la de Jean Franco. Véase Jean Franco. "Espectros de el Che", en Cuadernos de Literatura. Bogotá, 8 (15): 8, enero-junio de 2002.
} 
intransigencia, frialdad, intolerancia, energía, sobriedad. El Che, aseguran, era ceñudo, intenso, enfadado, erguido, altivo, tímido, tenaz, audaz, temerario y de arrojo inimitables, la voluntad siempre dispuesta al traspaso de los límites, a bordear el peligro con un sentido fatalista y trágico de la vida. Los adjetivos se acumulan para construir al personaje, ave de paso, espíritu de peregrino con alas en los pies dirigidos al encuentro de lo insólito, sediento de horizontes, soñador y bello, de inteligencia profunda e insaciable, interesado en relaciones intelectuales, Hombre que forjó una relación muy peculiar con la historia. Nunca fue esposo, pero sí amante; su vocación de viajero no se instalaba en relaciones amorosas permanentes. Se enamora y desenamora rápido. Las mujeres carecemos en él de horizonte: somos un breve detalle, un momento de satisfacción, 'un polvo rápido'. Su inteligencia lúcida no escapó a la mirada de gente como Raúl Roa, para el cual, este joven que sobresalía por su respiración asmática, aún si sereno y enérgico, de mirar y pensamiento profundo y palabra reposada, su risa clara irradiaba sus sueños mágicos.

Para Jorge Masetti (en Castañeda, 1998: 187) era un muchacho argentino típico de la clase media, parecido a un Cantinflas joven - a veces caricatura rejuvenecida del cómico mexicano, a veces Brad Pitt o George Cluny, digo yo, el hombre más hermoso del mundo, siempre en perpetua discusión política o poética pues poseía una pasión ilimitada por ambas.

Este es el Che aurático. El real no era fácil. En las discusiones, planteaba cualquier disyuntiva global rudamente y transformaba los desacuerdos en divergencias de fondo sobre altos principios filosóficos o doctrinarios cuando no en postulados morales y éticos. El Che no perdía nunca.

Leer sobre la vida de el Che es quedar asombrado de la gesta latinoamericana del siglo XX, con una política continental de arrastre que sale del útero de las dictaduras —Pérez Jiménez, Fulgencio Batista, Manuel Arturo Odría - hacia un ansia de igualdad y justicia democrática sin precedentes, y un tocar el cielo con las manos de toda la criollada metida en esa lucha. Son los blancos disidentes de los blancos; los blancos decepcionados de su propia raza o etnia; porque la gran mayoría de esos dirigentes progresistas son blancos volteados, burguesía blanca, media clase de izquierda, como bien caló Carlos Franqui a Fidel Castro. Los mayores marcan los pasos de el Che por el mapa latinoamericano, empezando por Paz Estensoro en Bolivia (1952 MNR), Jacobo Arbenz en Guatemala (1951-54 Primavera Guatemalteca), y terminando con Fidel Castro (1959 Movimiento 26 de Julio) - Che mismo, ese muchacho argentino típico de la clase media que ve Masetti, es un joven que se va radicalizando a partir de un sentido de rechazo por la injusticia y el maltrato que sufren las poblaciones de indígenas y de trabajadores pobres, tal como él pudo constatar con sus propios sentidos en su primera salida continental en moto.

Blancos y criollos sí, todos ellos, pero políticos social demócratas, siendo entre ellos el más brillante Fidel, que aprendió a mentir sin parpadear, a retener información y dosificarla en público a desinformar, maniobrar, despistar, confundir, ser implacablemente frío en sus alianzas y lealtades y a obedecer los imperativos de la realpolitik sin inmutarse. El Che conocía esa duplicidad e indiferencia, pero no las aceptaba. Fidel siempre andaba maniobrando, olisqueando, corrigiendo, matizando, y es en él que la burguesía de izquierda blanca se juega a radicalizarse por imperio de la necesidad histórica, cuando la política continental que ensaya políticas liberal-populares modernizadoras se topa de frente con el subdesarrollo. Las reformas eran insuficientes para los males seculares producidos por el colonialismo. Por eso se tira de lleno a la llama ardiente del cambio radical —el Che es uno de sus compañeros en esa América Latina, hervidero de exiliados, hiladores de sueños e ilusiones. Y es en esta lucha contra los enemigos y pseudo-amigos, externos e internos, elan de cambio, que participan y se enmarañan todas las fuerzas sociales: militares, partidos políticos en pugna, jóvenes estudiantes y trabajadores, empresarios y tecnócratas, la verdadera resistencia popular en el tira y encoge del clasismo y racismo coloniales sempiternos. Los Estados Unidos y los países socialistas, en guerra fría o coexistencia pacífica, observan con cuidado cada paso que dan los pequeños. Temen a Fidel, encantador de serpientes, 
hombre joven brillante, muy seguro de sí y de extraordinaria audacia. Nadie escapa de su embrujo. El Che dice:

Fidel me impresionó como un hombre extraordinario. Las cosas más imposibles eran las que encaraba y resolvía. Tenía una fe excepcional en que, una vez que saliese hacia Cuba, iba a llegar. Que una vez llegando, iba a pelear. Y que peleando, iba a ganar. Compartí su optimismo. Había que hacer, que luchar, que concretar. Que dejar de llora y pelear. (Castañeda, 1998: 148)

El plan de Fidel era una locura, pero una locura factible. La posibilidad de triunfo "al cual me ligaba [...] un lazo de romántica simpatía aventurera y la consideración de que valía la pena morir en una playa extranjera por un ideal tan puro" (Castañeda, 1998: 146) impulsó al Che hacia Fidel y la fascinación homosocial entre esos dos hombres fue, desde el comienzo, mutua.

Atrás quedó la derrota de Arbenz. En Cuba tendrán que medir la distancia entre sueños y retos: primero ganar la guerra en la Sierra y tomar la ciudad y, después, empezar a pensar en las políticas que se van a aplicar en la nueva creada república revolucionaria. El plan de reconstrucción es literalmente el sueño de la CEPAL, esto es, la modernidad desarrollista en vivo y en directo: su nervio central a discutir, el sistema de tenencia de la tierra, el monocultivo, y su substitución por una reforma agraria en la que se juegan el todo por el todo los nuevos dirigentes gubernamentales y sus bases burguesas y campesinas. Eliminar la lacra del latifundio, pensar una distribución más equitativa en pequeñas parcelas o en grandes cooperativas estatales, salir de la miseria, acabar con el analfabetismo, deseo que atraviesa de largo a ancho el continente. Y más aún de difícil realización, como lo demostrará el devenir histórico, perseguir la diversificación, la industrialización, la substitución de importaciones, transformar ciudades y el campo latinoamericano. El Che va más allá: quiere ser autosuficiente, libre, pero en esto parece no tener idea de la necesidad histórica, o descalificarla —infantilismo de izquierda, llamará a esto, Lenin. Porque en estos planes hay más protagonistas que el de los guerrilleros, que el de los líderes social demócratas. También juegan un decisivo papel los otros blancos y no blancos, los empresarios y tecnócratas capitalistas y las bases campesinas indígenas, negras o mestizas; y todas las fuerzas se sitúan en estado de alerta respecto a estas nuevas ideas. No van a estar contentas con la propuesta del monopolio estatal de la tierra, de los recursos, de bienes e ideas - ni ellas, ni sus aliados extra-territoriales. A ese amplio, vasto y conflictivo panorama también nos asoma repasar la vida de el Che.

En ese momento, la tierra es el aspecto toral; sobre ella se polarizan las otras fuerzas sociales y, en este mar revuelto, hay que tener o desarrollar criterios, astucia política y saltarse o sobrevolar ideales y deseos; y aquí podemos tocar con las manos un parte aguas entre Fidel y el Che: el primero, supremamente pragmático y de sensibilidad política neural; el segundo, arrebatado por la prisa y el voluntarismo propios del que se considerará 'aventurero idealista,' como le llamó un funcionario de la Embajada Norteamericana —o infantilismo de izquierda pequeño burgués, a la usanza soviética.

Necesidad y urgencia son las determinantes que abrirán el hiato entre Fidel y el Che, entre la insurgencia y el manejo del Estado, cesura que se va a ir ensanchando y dará cuenta quizás de la separación de estos dos pro-hombres continentales, la eventual salida del Che de Cuba, primero hacia los países Orientales, luego a Europa y al África y, finalmente, a Bolivia donde encontramos el principio del fin, el juego de la guerra de guerrillas, sueños de papel. Su condición física, su pseudo-narcisismo y su voluntarismo lo llevarán a ese cul-de-sac de la Higuera donde es finalmente capturado y dejado a su aire por las fuerzas de Fidel. ¿De qué realmente se percató el Che en Bolivia? Ahí está el detalle: quizás, las políticas realistas de Fidel supieron con bastante antelación que los deseos de el Che habían alcanzado su zona liminal.

Porque según se dice, esos dos hombres eran afines, y el respeto que se procuraban era el de cómplices natos, sentido de amistad entrañable que no se tiene que explicar porque se leen el pensamiento, hombres ambos de extraordinaria audacia y sagacidad. Pero de entre los dos, solo Fidel 
poseía la intuición política deslumbrante para arrodillarse frente a la necesidad histórica y darse cuenta de que la revolución no es sólo un líder, sino una vasta red de dirigentes sindicales, estudiantiles, comunistas e incluso algunos empresarios más la inmensa maraña global dentro de la cual finalmente quedó cautivo. $Y$ es en ese momento que el Che se va, rota no la cercanía sino la fidelidad al imperio de la necesidad en uno y la de probar fortuna en el otro. ¿Acaso supo el Che al ser capturado que la necesidad política no es una procesión que puede parar el santo? Lo político requiere una cautela inenarrable y una decisión que, aunque dolorosa, hay que ejecutar. Fidel deja al Che solo en Bolivia cuando se da cuenta que esa aventura es ya una enfermedad terminal.

Ya después de 1959, las divergencias entre distintas facciones del 26 de Julio habían enseñado que el consenso es de difícil mantenimiento. Aparecieron pronto en Cuba las facciones entre sierra y llano, revolucionarios y liberales, partidarios de una junta militar y defensores de la lucha hasta el final. La revolución se empieza a radicalizar y Fidel a alejarse de sus aliados liberales. La reforma agraria es un punto agrio: pasa por la estatización de la tierra y formación de cooperativas de las propiedades azucareras, cafetaleras, tabacaleras y de otros cultivos. La destrucción de latifundios y anulación de la indemnización forzosa y previa en dinero constante y sonante, es un fuente constante de discordia - ya le había sucedido a Arbenz en Guatemala - y trajo consigo el descontento de los empresarios ricos, dueños del azúcar, y de sus aliados norteamericanos quienes, después del éxodo masivo de cuadros cubanos, organizaron la invasión fallida a Playa Girón, misma que con el tiempo escaló en un bloqueo que dura todavía y en una crisis de los misiles que dejó perplejo a los Estados Unidos.

La discusión sobre las políticas nacionales cubanas, de gran intensidad y nervio, terminó en una encerrona en la que la economía se iba al abismo día a día y, para sobrevivir, la alianza con la Unión Soviética era la tabla de salvación para mentalidades anti-imperialistas. Se aprende que los países sin presupuesto no pueden pensar en desarrollos sostenidos independientes. El consenso cepalino tan propicio y esperanzador para establecer la alianza de clases basada en la modernización, el deseo de industrialización vía sustitución de importaciones, diversificación de mercados, suministros y productos de exportación, papel determinante y central de un estado fuerte e intervencionista en la economía y la sociedad en el que estaban de acuerdo revolucionarios marxistas y comunidad tecno-empresarial, se hace trizas ante las variables estatales de una reforma agraria radical. Se habló entonces de un 'guerillerismo administrativo', dogmático pues, la radicalización de la revolución escandaliza. Destruido el régimen antipopular, urgía abolir el sistema social dictatorial y sus fundamentos económicos, formar el ejército revolucionario, eliminar disidencias, reeducar a la gente, establecer el trabajo voluntario, la transferencia masiva de mano de obra de un sector a otro, traer expertos soviéticos en áreas claves de la economía y la política porque cuadros no había. Esta acrobacia conducía a vincular la sobrevivencia de la isla al paraguas de la URSS. Los Estados Unidos no los iba a dejar a los cubanos experimentar libremente con una economía y una sociedad pegadita a sus costas; no los iba a dejar reorientar a vapor todo el sistema económico hacia otro bloque económico.

Es la hora de las definiciones duras. La necesidad política requiere contención, aguante. El Che no es de los que se queda callado. La relación entre estos dos gigantes continentales con sueños idénticos, pero procedimientos encontrados se iba a deshilachar. Y así, después de la gesta fallida, pero gesta, no obstante, desembocamos en la idea de varios Vietnams, la guerra de guerrilla, la revolución continental y el nacimiento del hombre nuevo. Sueños de opio porque las fuerzas opuestas también calendarizan su ofensiva, empezando por la Alianza para el Progreso, seguida de la organización y entrenamiento de ejércitos, la Operación Cóndor, que pondría en situación de mando a los hombres que servirían como agentes locales de los intereses empresariales de un capitalismo que se empieza a cosmopolitizar. Con ello, las ideas de Fidel también encontraron su punto liminal. Sólo le quedaba el muñequeo político y defect to the east. 
Así, el texto sobre Guevara de Castañeda vuelve al sur, para decirlo en clave de tango, "como se vuelve siempre al amor / [...] / con su deseo y su temor / [...] / como un destino del corazón" (Astor Piazzolla y Fernando E. Solanas). Texto masculino, de homosocialidad tan asentada como cautelosa, que se abre a la femineidad nada más ni nada menos que con una invocación a Sor Juana en su poema, "Coplas del alma," de donde extrae el verso "Muero porque no muero," que titula el capítulo, pero que también es parte del poema "Vivo sin vivir en mi" de esa otra monja, Santa Teresa de Jesús, cuya primera estrofa dice:

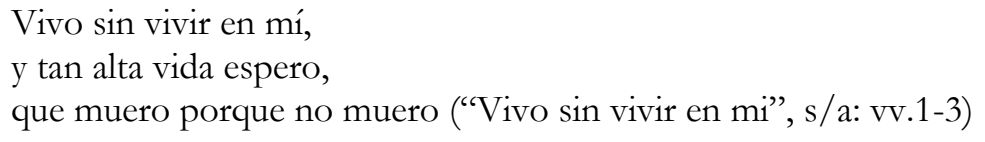

Amarrados a estos referentes, ni siquiera tenemos que preguntamos por el ubi sunt de los admiradores enamorados de el Che, como lo fuimos todos los de esa generación, hombres y mujeres, pero de diferente manera. Porque las mujeres, constituidas en y por el amor romántico y el permiso de ser en ello que el género conlleva, podíamos ampliar nuestro radio de acción hacia los otros héroes culturales del momento, digamos con afán consistente, James Dean o los Beatles, mientras los hombres, no; porque, ¿cuáles, entre el amplio repertorio de figuras, valía más que el Che? ¿Quiénes, preguntamos, gozaron del alcance del que, para todo propósito continental, norte-sur, este y oeste, será para siempre no Ernesto Guevara, sino El Che, ese 'aventurero idealista', que desplegó sus alas y cubrió el universo entero, desde México, extremo norte, hasta lo que llamamos con afán poético, Cono Sur?

Para las sensibilidades masculinas, el camino hacia lo erótico lo pavimentó el espíritu de aventura disimulado en lo político, condición de posibilidad que autoriza la expresión de la sensibilidad masculina por lo masculino, igual que lo hacen los deportes, y el sentido afectivo trasmutado y medio disimulado en admiración ante la gesta y los hechos que se pueden leer en todas y cada una de las frases del texto de Castañeda, texto egregio, que leo de manera sintomática, aun en aquellas expresiones que pretenden ser críticas, como las que se refieren a las políticas duras e irrealizables que se propuso implementar el Che en cuerpo y alma en la Revolución Cubana — disparates en los que pretendía que lo económico debía ocupar un lugar secundario en lo político y que se debían abolir entre la gente las relaciones de mercado basadas en el dinero, salario, intercambio, competitividad y rivalidad, y regirse por otro tipo de reglas. ¡Hermosísima quimera!

Pero donde el texto de Castañeda despliega todo el afecto, el enamoramiento como admiración de la personalidad de un hombre transformado en héroe de ficción, es en la selva boliviana que emparenta consanguíneamente la gesta de el Che con la novela de la selva y hasta con lo real maravilloso —ensamble o trasmutación de aquellas ficciones modernistas sobre el desarrollo. Su gesta camina muy pegadita a esos héroes que dan volteretas sobre su propio eje, Arturo Cova o el coronel Aureliano Buendía. Narrativas del ansia de modernidad y desarrollo mediatizada por lo político, como argumentará más tarde Laclau (2001) para el caso del papel que jugó el partido comunista o la noción de vanguardia en la revolución rusa. Este desliz de un género a otro, del ensayo a la novela y del análisis sociológico a la ficción, que llamamos transdisciplinario, lo facilita un tipo de agencia y comportamiento que encuentran su fulcrum genealógico en ese héroe de mil batallas, derrotado por un devenir histórico clausurado en sus procesos de cambio por la historia colonial-imperial. Eso lo encarna así mismo a completud el Che.

Más como personaje que como político, "El Che vivo inspiraba lástima [...] pero infundía escepticismo sobre su identidad. O comprobaba el asesinato inconfesable, aunque de todos conocido" (Castañeda, 1998: 18). En la muerte predomina la imagen crística laica, almita del Che, objeto de deseo masculino; mientras la otra, la sombría y destrozada, como por encanto se empezó a evaporar al entrar en ese cuartito desvalido, lavandero de ropa, donde lo colocaron para asegurarse de sus señas de identidad. Es en ese momento, cuando le pusieron el pañuelo en la mandíbula, cuando pudieron verlo 
sin que él los viera, y extasiarse real y narrativamente en su ciega mirada de muerte, que pudieron asegurar, falsamente, que "no se sufre cuando se muere por ideas" (Castañeda, 1998: 17).

El drama entra en crescendo cuando "Despejaron su rostro, ya sereno y claro, y le descubrieron el pecho diezmado por 40 años de asma y uno de hambre en los páramos del sureste boliviano" (Castañeda, 1998: 16). Drama no como el de Edipo Rex, que es tomado por sorpresa, a ciegas, por su hubris; drama porque el Che se la busca y la encuentra, la encuentra y marcha directo hacia ella, la llama ardiente, con toda la intencionalidad de la que es capaz, porque en él predomina sobre el pesimismo de la razón, lo que Antonio Gramsci llamaría optimismo de la voluntad, y los partidos comunistas y organizaciones políticas, desviacionismo pequeño burgués, voluntarismo y hasta omnipotencia arrogante. Estamos en plena coexistencia pacífica.

El voluntarismo pequeño burgués era el estigma con que los partidos comunistas marcaban la desviación de sus intereses continentales particulares, y el Che era voluntarista. Ese era su atractivo. Castañeda llama a este rasgo de personalidad, 'cuasinarcisismo' para otorgarle las indulgencias y permitirle una salida airosa de ese aspecto devastador de la personalidad por el huequito del adverbio. El Che se sentía omnipotente; pensaba que lo podía todo; ninguna contradicción le haría mella o disuadiría de perseguir su meta hasta alcanzarla; tozudo, resolvería toda pulsión apoyándose fervientemente en la fuerza de su voluntad. Si algo fallaba, era responsabilidad ajena, no suya. Mas el asma es el síntoma que traiciona su angustia de sujeto; seña indeleble de la duda ante la ambivalencia del mundo; señuelo al aire libre de eso que tiene prohibido revelar o aceptar y que, al resguardarlo, haciendo uso de todas las fuerzas de su voluntad, lo ahoga. Si su fe ciega en la fuerza de la voluntad subraya su hombría, el asma denota una vulnerabilidad situada socialmente en lo femenino. La ambivalencia, la contradicción, las tensiones entre compañeros, la dura realidad que resiste la transformación material y subjetiva, los irreducibles cambios culturales a los que se somete, las situaciones límites, los peligros inminentes, pero también el polvo, las alergias, los cambios de clima se suman a todos esos imponderables afectivos, subjetivos y biológicos que se tornan ahogo en los severos ataques de asma. Y en este cuerpo debilitado, en estos bronquios y pulmones que reciben las descargas de adrenalina que surgen del medio ambiente físico, pero también del combativo, de la alerta en el ataque, del temor a la emboscada, de la pérdida de la brújula, de la realización que lo han dejado solo, pueden desatarse episodios pulmonares mortales.

El Che está dispuesto a cruzar todas las fronteras, pero sus pulmones frágiles y bronquios cerrados lo desfavorecen. Como proto-agon se enmarañará en lo real de la real selva boliviana que lo captura y enreda, lo enyuya hasta dejarlo en el más absoluto abandono, el cordón umbilical que lo oxigenaba desde un lejano país del Caribe americano, roto. También quedará preso el Che en el discurso de inteligencia y contrainteligencia de corte partidario, hora de la coexistencia pacifica y el socialismo en un solo país, no de la lucha armada, el foco guerrillero, creación del hombre nuevo e internacionalismo solidario y combativo. Todo apoyo logístico clausurado. Su contacto con La Habana, Renán Montero, ha sido desalojado de La Paz y trasladado a otra parte del universo. El Che queda a merced de su hubris y, como Edipo Rex, cierra, con su periplo cumplido, el de la ideología política de izquierda como solidaridad proletaria y utopía a realizar, y abre el principio de la realpolitik. En este preciso instante, el Che pasa de lo político a lo poético y, justamente ahí donde falla, triunfa.

Aquel afecto que sintió por el pueblo inspirado en los mineros e indígenas bolivianos, en los guajiros cubanos, que requerían o justificaban, según él, derramamientos de sangre, armas, furia para liberarse, pasaba ahora en ese pueblo de mierda a ser combatividad desbrujulada, desvalida, desencuadrada, ceguera pura y dura ante las conquistas que podrían haber traído las armas. La hidalguía y nobleza de los pueblos, o del sujeto pueblo, pasa a ser solo un leitmotif que posibilita narrativas idílicas, pretextos para argumentar la trama de las narrativas de cambios modernizantes, insurgentes, esperanzadores de la tan deseada revolución continental americana. 
Ese hombre que empezó su vida como vago, fotógrafo ambulante, investigador médico, exiliado permanente, esposo de ocasión, hombre desocorrido, se eleva a nivel de emblema de la aspiración del cambio continental. El Che tuvo la oportunidad de ver y participar en toda la maravilla producida de principio a fin por esa lucha donde reformistas, moderados, constitucionalistas, promotores de la reforma agraria, el reparto de utilidades, la confiscación de tierras, la reforma educativa, la nacionalización de los servicios públicos y telefónicos, la reforma de la vivienda y el radicalismo populista convergieron en el terreno pantanoso de la historia política colonial y colonialista americana. El Che conoció de cerca esos experimentos sociales del siglo, fue copartícipe de ellos, siglo que fue de luces y de sombras, prueba de fuego donde elementos desgajados de las oligarquías blancas, ya dije, desertaron de su grupo social para establecer unas nacionalidades más completas y abarcadoras, más horizontales, justas y multiculturales, para perder ante el embate de un capitalismo corporativista global que se fortalecía día a día, y de un socialismo cada ves más autoritario y totalitario.

La guerra de guerrillas que iba a liberar a la América Latina se basaba en un desprecio a esas burguesías nacionales constituidas, trabajadas y aprovechadas por los blanquitos criollos, y la disolución del sistema de tenencia de la tierra en latifundios responsables de la miseria del campesinado pobre. Esas eran las dos clases raigales en pugna. Que sólo 321 rebeldes hubiesen ganado la guerra a 10 mil soldados batistianos en Cuba no significaba que la lucha sería igual en Bolivia, país donde la idea era establecer relaciones dentro de las fuerzas armada y la burguesía gobernante y, después, extender el contacto con todos los países latinoamericanos. La suerte estaba echada, los dados cantados. Mas Bolivia no era Cuba. El ejército, formado por los alemanes a principio de siglo, poseía un sentimiento nacionalista; contaba además con milicias campesinas y obreras surgidas de la revolución que imbricaban campesinos, caciques y militares; su movimiento obrero, altamente politizado y concentrado en las minas de estaño y antimonio, se organizaba en la poderosa Confederación Obrera Boliviana. Además, la Alianza para el Progreso había permitido a las fuerzas armadas tomar iniciativas políticas en las necesidades locales de la población, tales como la construcción de escuelas y caminos en las zonas rurales. Bolivia era el peor lugar para un lanzamiento revolucionario.

Fidel sabía todo esto y más y trató de disuadir a el Che, hablándole de las dificultades de la expedición y reticencias del Partido Comunista Boliviano. Para el foco faltaban comunicaciones eficientes, población y campesinos sin tierra, vegetación, fauna, agua para que las guerrillas sobrevivieran. El Che no oyó razón porque para él, Bolivia era una salida, un foco madre, a pesar de las dificultades. Por tanto, Castro lo respalda, le arma la expedición; le da 21 hombres, dinero, casas de seguridad, documentos, equipo. Se les unirían después 60 bolivianos, núcleo inicial para crear el foco guerrillero. El equipo logístico incluye a Tamara Bunke y Regis Debray; Renán Montero será trasladado a La Paz para mantener el contacto con ellos. La escuela de cuadros guerrilleros para América Latina quedaría localizada en la cuenca del Río grande, su teatro de operaciones.

Fidel sabe que el Partido Comunista boliviano se coloca entre azul y buenas noches. Mario Monje, su secretario general, alejará a el Che de la lucha armada en Bolivia y lo desviará hacia Ñancahuazú, ratonera que lo acercaba lo más posible a la Argentina. Contra toda prudencia, el Che arma su cuartel general transformando una finca en parapeto de guerra y teatro de operaciones con sistema de comunicación, cuevas, y escondites de comida, medicina, equipo y documentos. Monje le propone unirse a él, pero pide la construcción de un amplio frente continental y combinar la lucha armada con un esquema insurreccional en las ciudades. No lo convence. El Che queda a su aire y la narrativa que lo acompaña mezclan el relato insurgente y contrainsurgente con la novela de la selva. Leamos:

El periplo, inicialmente previsto para durar 25 días, se prolonga por más de seis semanas, horriblemente arduas, agotadoras y desgastantes. Recorren cañones, cuencas de arroyos convertidos en ríos, caminos y pequeñas aldeas casi deshabitadas; exploran los farallones y desfiladeros hasta el río Grande y el río Masicuri [...] La vegetación espinosa y tupida, los mosquitos y otros insectos [...] la penuria de fauna para promover la alimentación de las tropas, las lluvias y los ríos crecidos, 
conforman un cuadro dramáticamente distinto al de la Sierra Maestra al que El Che esperaba. Los exploradores se ven obligados a abrirse paso con machete; al tercer día, lo accidentado del terreno priva a varios combatientes de sus botas. El hambre y la sed los agobian; los reclutas agotan su dotación de alimentos antes de tiempo, y el Che comienza de nuevo a aplicar la madre de todas las sanciones: suspender la comida. Al consumirse las raciones, deciden devorar el caballo que habían comprado días antes. (Castañeda, 1998: 574)

Pronto, el Che empieza a mostrar fatiga, impaciencia y mal humor y cuando vuelve a la base el 20 de marzo se encuentran todos

devastados por casi siete semanas de hambre, sed, agotamiento y disensiones. Al ver al Che por primera vez, sus visitantes se estremecen: era un hombre emaciado, con 20 kilos menos, con la cara, las manos y los pies hinchados [...] la cobertura del campamento, de la guerrilla y del mismo comandante se habían hecho añicos. Las deserciones del grupo de Moisés Guevara, las sospechas de los vecinos y el trabajo de inteligencia de los bolivianos y de la CIA, así como los encuentros con varios técnicos petroleros de Camiri, alertaron al ejército boliviano, el cual de inmediato se dirigió a la finca de Ñancahuazú [...]. En marzo, cuando Moisés Guevara se trasladaba de manera definitiva al campamento, acompañado por Tania y Coco Peredo, fue seguido [...] por la policía [...]. El 14 de marzo se toparon con la policía, que los entrega a la Cuarta División, donde suministran una información completa y detallada acerca de la guerrilla, el campamento, el número de hombres y, sobre todo, de la presencia del Che Guevara, sus alias, sus fechas de ingreso al país, y varios detalles más. (Castañeda, 1998: 575)

Este movimiento sigiloso que pertenece al género contra-insurgente de la guerra fría, emparenta estas narrativas a las de John Le Carré como Tinker Tailor, Soldier, Sailor (1974) donde agentes y dobles agentes constituyen la trama. Se dijo, por ejemplo, que Tania era doble agente, de la KGB y del Ministerio de Seguridad del Estado alemán oriental, candidata natural por su origen argentino a trabajar en el ámbito internacional. Su enamoramiento del Che cruza afecto y política que nunca se desamparan. Luego se interrumpen las comunicaciones, cae la red urbana, se cortan todos los nexos, desaparecen los aparatos transistores y La Habana sólo puede saber de el Che mediante los cables de prensa. Como a Arturo Cova, se los había tragado la selva.

Seguidos de 600 rangers bolivianos, el pequeño ejército loco con sus dos unidades incomunicadas, buscándose durante cuatro meses en las serranías bolivianas, en ocasiones en cercanía los unos de los otros e incluso abriéndose fuego sin establecer contacto, se mueve el Che y sus hombres por esos descampados a la vista de todos. Se cruza primero con una vieja acompañada de su hija enana, luego pasan cerca de un campesino que cultivaba su siembra de papas bajo el resplandor lunar. Ambos lo denuncian. Sus captores no saben exactamente cómo disponer de él. Sin duda vale más vivo que muerto, pero no lo vieron así, como tampoco vieron lo que vio Freddy Alborta en su pétreo lecho de muerte: el Che era el semblante de Cristo, una luminiscencia ocular, una enorme melancolía y todas las batallas futuras por librar.

Recorrer el camino de la vida de el Che es revisitar, como hemos podido constatar, las profundas discusiones que caracterizaron el siglo XX americano. A través de el Che hemos oído a sus intelectuales dialogar, a sus poetas versificar, a sus jóvenes combatir y morir en las guerras sucias hechas a la medida de muchachos que querían tomar el cielo por asalto y remediar todos los males creados por el colonialismo, afianzados por el imperialismo, y apoyados por sus élites nacionales blancas. Nos damos cuenta de por dónde iba la cosa no sólo en el imperio sino en el mundo comunista que defendían la idea del socialismo en un solo país. 


\section{Epílogo}

Viajando de Medellín hacia la frontera con el Ecuador en un autobús decrépito, veo el retablo que se ha hecho el chofer. Ahí está la virgen María, Cristo Crucificado, Armando Manzanero, El Santo, Pablo Escobar, un rosario colgado, unas flores de papel, la estampita de una iglesia, el retrato de alguna novia, la imagen de Marilyn Monroe, Cantinflas, Mohamed Ali y al centro del retablo la foto de Alberto Korda de el Che, justo la que le devolverá la juventud, la vida plena que cubre el siglo XX latinoamericano, siglo de luces y tinieblas. Ecce homo, el señalado, cuya imagen es sólo comparable a la del crucificado o a la del más famoso cantante de rock — stand by me.

\section{Bibliografía}

Anderson, Jan Lee (1997), Che Guevara. A Revolutionary Life. Nueva York, Grove Press.

CASTAÑEDA, Jorge (1998), La vida en rojo. Una biografía del Che Guevara. Debolsillo-ebook.

Franco, Jean (2002), "Espectros de el Che”, Cuadernos de Literatura. Bogotá, vol. ' 8, n. ${ }^{\circ}$ 15, enerojunio de 2002, pp. 89-105.

LACLAU, Ernesto (2001), Hegemony and Socialist Strategy. Londres, Verso.

LE CARrÉ, John (1974), Tinker Tailor, Soldier, Sailor. Nueva York, A. Knopf.

Piazzolla, Astor y Solanas, Fernando E. (1988), "Vuelvo al Sur" (canción).

RiverA, José Eustasio ([1924] 1990), La Vorágine. Madrid, Cátedra.

SAER, Juan José (2015), El Entenado. México: Elefanta Editorial, e-book.
SANTA TERESA DE Jesús (s/a), "Vivo sin vivir en mi". $<$ https://www.santateresadejesus.com/poesias/>.

TAIBÓ II, Paco Ignacio ([1996] 2017), Ernesto Guevara también conocido como el Che. Barcelona, Planeta Libros. 